\title{
MEIO AMBIENTE, SAÚDE E CULTURA INDÍGENA: A COLISÃO ENTRE DIREITOS FUNDAMENTAIS NA COMUNIDADE INDÍGENA KAINGANG DO ACAMPAMENTO PRÓXIMO À RODOVIÁRIA DE SANTA MARIA/RS ${ }^{1}$
}

\author{
Seila Mello \\ Angelita Woltmann ${ }^{3}$; \\ Raquel Buzatti Souto ${ }^{4}$
}

\begin{abstract}
RESUMO
A presente pesquisa tem, neste primeiro momento, a finalidade de instigar a comunidade científica acerca da situação dos índios kaingang, acampados nas proximidades da rodoviária de Santa Maria/RS, frente à colisão de direitos fundamentais, no intuito de investigar a atuação do Estado na busca da efetivação dos direitos indígenas, sem descaracterizar a diversidade cultural dessa população que, atualmente, encontrase reduzida, devido à inserção do "homem branco" fazendo valer a sua hegemonia e autonomia. Nesse viés, diante de um abalroamento de direitos fundamentais - notadamente, entre o meio ambiente, saúde e cultura indígena - buscar-se-á trabalhar com a hipótese da ponderação entre seus valores, partindo-se de um entendimento que assegure acima de tudo o princípio da dignidade humana.
\end{abstract}

Palavras-Chave: Direitos Humanos. Índios. Estado. Constituição Federal de 1988.

\footnotetext{
${ }^{1} \mathrm{O}$ estudo a ser feito não se estende a toda a população indígena da cidade de Santa Maria, delimita-se à "Comunidade Kaingang do Acampamento próximo da Rodoviária” e está sendo realizado como resultado de PIBIC/UNICRUZ. Diante do impacto gerado por tal comunidade indígena, questiona-se: cerca da possibilidade de proteger o meio ambiente da cidade de Santa Maria através de físcalização contínua, ao mesmo tempo, proteger os interesses e a cultura da comunidade indígena que ali vive analisando a possibilidade de criarem-se políticas públicas de educação ambiental para que os indígenas aprendam a cuidar do meio ambiente em que vivem, separando seus resíduos sólidos e dando a eles destinação adequada, com o apoio do Município.

${ }^{2}$ Estudante da décima fase do curso de Direito pela Universidade de Cruz Alta- UNICRUZ. Estagiária da Justiça Federal e Juizado Especial Adjunto Subseção de Cruz Alta. Bolsista do PIBIC 2012-2013 denominado "Comunidade indígena "kaingang" na cidade de Santa Maria/RS: é possível fiscalizar e proteger o meio ambiente sem prejudicar a cultura indígena?”. E-mail: mellosantos.13@gmail.com.

${ }_{3}^{3}$ Doutoranda em Ciências Jurídicas pela Universidade de Buenos Aires. Mestre em Integração LatinoAmericana pelo Mestrado em Integração Latino-Americana (MILA) da Universidade Federal de Santa Maria (UFSM) na linha de pesquisa Direito da Integração. Especialista em Direito Constitucional aplicado pelo Centro Universitário Franciscano (UNIFRA). Especialista em Bioética pela Universidade Federal de Lavras (UFLA). Coordenadora do Curso de Pós-Graduação Lato Sensu em Direito Civil e Processual Civil - $5^{\mathbf{a}}$ Edição. Professora da Universidade de Cruz Alta (UNICRUZ). Advogada. Coordenadora do PIBIC 2012-2013 denominado "Comunidade indígena "kaingang" na cidade de Santa Maria/RS: é possível fiscalizar e proteger o meio ambiente sem prejudicar a cultura indígena?”. E-mail: awoltmann@gmail.com.

${ }^{4}$ Professora e Coordenadora do Curso de Direito da UNICRUZ. Mestre em Desenvolvimento, linha de pesquisa Direito, Cidadania e Desenvolvimento pela Universidade Regional do Noroeste do Estado do Rio Grande do Sul (UNIJUI). Especialista em Direito Constitucional Aplicado: uma abordagem material e processual pelo Centro Universitário Franciscano (UNIFRA). Coordenadora do Curso de PósGraduação Lato Sensu em Direito Civil e Processual Civil - $5^{\text {a }}$ Edição. Membro do Conselho Editorial da Revista Eletrônica do Curso de Direito da UNIME. Colaboradora do PIBIC 2012-2013 denominado "Comunidade indígena "kaingang" na cidade de Santa Maria/RS: é possível fiscalizar e proteger o meio ambiente sem prejudicar a cultura indígena?”. Advogada. E-mail: rsouto@unicruz.edu.br.
} 


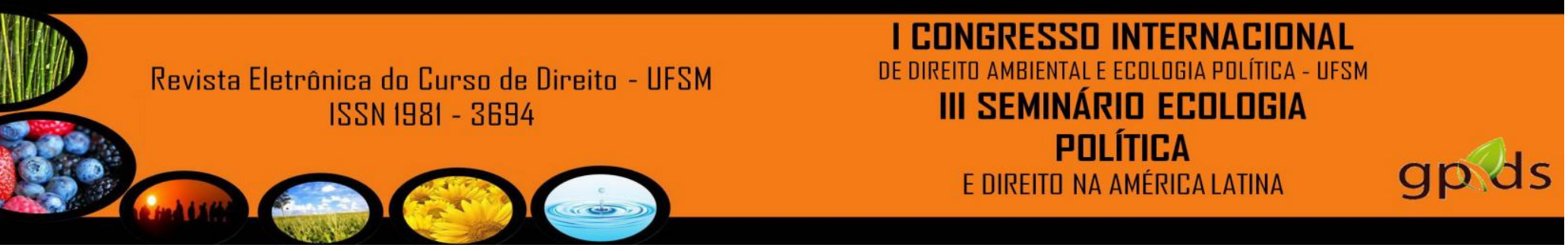

1 CONSIDERAÇÕES INICIAIS

Contrariamente ao que se acredita, o êxodo indígena do meio rural para o urbano não é um acontecimento contemporâneo. Desde meados do século XVIII, quando ocorreu o desmonte das missões indígenas, essa migração vem ocorrendo de fato.

As razões pelas quais deixam sua aldeia e passa a viver nos centros urbanos variam $^{5}$. A ausência de apoio governamental e os problemas ambientais cada vez mais graves deixam populações indígenas desamparadas, muitas vezes até com falta de recursos e de comida. Em razão disso, alguns índios buscam na cidade melhores condições de adaptação, adequando-se aos costumes urbanos e buscano trabalho e estudo. Também são causas do êxodo as freqüentes invasões dos fazendeiros aos territórios ocupados pelos índios, conflito de terra que muitas vezes resultam na morte de muitos indígenas, incluindo suas lideranças. Esses conflitos $\mathrm{e}$ as mortes amedrontaram o povo índio, causando fuga em massa de suas aldeias. Nesse sentido,

A problemática da terra, pode se dizer, é hoje a principal razão da migração e dos conflitos. As origens da atual estrutura agrária e social da região estão no século XIX. "Foi naquele período que se formaram as grandes propriedades pastoris e surgiram os primeiros camponeses sem terra quando, paradoxalmente, havia milhares de hectares de terras virgens" (ZARTH, 1997.p. 12).

Foram principalmente os camponeses de origem luso-brasileira, conhecidos como caboclos, ao lado dos indígenas, os principais afetados quanto à perda de grande parte de seus territórios. Estes eram considerados atrasados, contrariamente ao imigrante - notadamente o descendente de alemães e italianos - , trabalhador e símbolo do progresso.

Este processo de ocupação da terra, suas relações de trabalho e sua presença na formação da estrutura social, relacionando com a chegada do imigrante e seu acentuado desenvolvimento econômico, político, social e cultural, certamente foi fator preponderante para que os índios kaingangs também saíssem do meio rural, na tentativa de melhore condições de vida na realidade urbana.

\footnotetext{
${ }^{5} \mathrm{O}$ censo do IBGE não permite saber se as 383.298 pessoas que vivem nas cidades e se autoidentificaram como indígenas estão diretamente ligadas a povos ou se apenas identificam-se com este grupo. Mas o próprio IBGE avalia, em publicação que analisa os resultados da amostra dos censos de 1991 e 2001, que o crescimento expressivo da população indígena no Brasil no período está diretamente ligado à autoidentificação que ocorreu nas cidades, e não no campo. E que este é um fenômeno que precisa ser mais estudado. (CARVALHO, 2007, s.p)
} 
III SEMINÁRID ECDLDGIA

PDĹ́TICA

E DIREITO NA AMÉRICA LATINA

A chegada dos colonos determinou o surgimento de novos aglomerados

populacionais, que mais tarde formaram novas cidades, estruturando uma nova base político-administrativa, com influências na política regional. A ocupação do Rio Grande do Sul não foi um processo pacífico, tendo vários conflitos históricos ${ }^{6}$ que deixaram problemas mal resolvidos em virtude das heterogeneidades. Assim, a história brasileira

[...] é uma história dos que mandam e, particularmente uma história dos que participam do pacto político. A mesma exclusão, aliás, afeta também o índio. Até hoje não se reconstituiu a história das lutas indígenas no Brasil, as formas do confronto entre índios e brancos que continuam até nossos dias (...). A história do Brasil é a história das suas classes dominantes, é uma história de senhores e generais, não é uma história de trabalhadores e rebeldes. A história oficial não costuma registrar feitos de derrotados. (MARTINS, 1983. p. 26).

Embora em número reduzido, a maioria dos índios nos séculos XVI e XVII migrou para a Província do Guairá ${ }^{7}$, sabendo-se que alguns grupos ancestrais dos atuais kaingang foram reduzidos em Conceição dos Gualachos, às margens do rio Piquiri, e em Encarnación, às margens do Tibagi. Após fuga dos bandeirantes paulistas, os jesuítas fundaram novas reduções na Província do Tape, entre 1632 e 1636 (atual Estado do Rio Grande do Sul). Baseando-se em alguns registros históricos, é possível que os kaingang tenham sido influenciados pela redução jesuítica da Santa Tereza, na região de Passo Fundo, e desde então buscam espaço em cidades. (INSTITUTO SÓCIO AMBIENTAL, 2000).

Conforme tabela confeccionada por Veiga e D'Angelis (2006), as aldeias concentram-se em sua grande maioria nas cidades do centro e norte do Estado do Rio Grande do Sul, entretanto o destino de sua migração não possui estatística de fato em razão de não possuírem, na maioria das vezes, moradia fixa e vínculo empregatício.

No caso dos kaingans moradores das proximidades da rodoviária de Santa Maria $^{8}$, de acordo com a entrevista realizada em 15 de abril de 2012, o representante da tribo diz o seguinte:

Viemos de várias aldeias (Reserva de Guarita, Tenente Portela, Redentora, Palmeira das Missões). Nosso meio de transporte... viemos em ônibus particular (pago). Estamos aqui mais ou menos desde 2008 nesse local, mas acampamos aos arredores há mais de 10 anos. (sic)

\footnotetext{
${ }^{6}$ A exemplo da Guerra Civil dos Farrapos e a Revolução dos Maragatos, em 1893-95. (FLORES, 2010).

${ }^{7}$ Atualmente, ocupa grande parte do estado do Paraná.

${ }^{8} \mathrm{Na}$ mesma entrevista, o representante da tribo diz que no acampamento vivem sete famílias, mas, mais ou menos duzentos índios passam em datas especiais. ENTREVISTA COM O REPRESENTANTE DO ACAMPAMENTO KAINGANG DA RODOVIÁRIA DE SANTA MARIA, 2012)
} 
III SEMINÁRII ECOLOGIA

PDLÍTICA

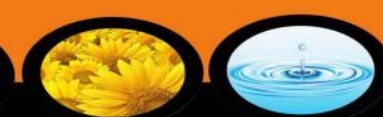

E DIREITO NA AMÉRICA LATINA

(ENTREVISTA COM O REPRESENTANTE DO ACAMPAMENTO

KAINGANG DA RODOVIÁRIA DE SANTA MARIA, 2012)

O que é preciso ficar claro é que não se pode confundir um povo que encontra dificuldades em concretizar seus direitos em virtude de sua vulnerabilidade causada pela discriminação e omissão do Estado - como acontece com o povo kaingang - com um povo sem direitos fundamentais.

Assim, embora a pesquisa também tenha um delineamento voltado para a educação ambiental, está sendo enviada para apresentação no simpósio 07, sobre "Ecologia política e direitos humanos", justificando-se por, nessa etapa, ser trabalhada a questão da colisão entre os direitos fundamentais dos kaingangs.

\section{DA AFIRMAÇÃO HISTÓRICA À COLISÃO DOS DIREITOS ENVOLVIDOS}

Os direitos fundamentais foram identificados, historicamente, com os valores mais importantes da convivência humana, ou seja, aqueles sem os quais as sociedades acabam perecendo, fatalmente, por um processo irreversível de desagregação (COMPARATO, 2003). Todos os seres humanos ${ }^{9}$ são destinatários dos direitos fundamentais, e, deste modo, os indígenas, mesmo que desprivilegiados pela história, são alcançados em plenitude pelas normatizações.

Posto isso, é difícil pensar em que consistem os direitos fundamentais da pessoa humana e sua evolução sem relacioná-los à história, pois estes são construídos ao longo de anos, frutos de pesquisas e, principalmente, lutas contra o poder. Nesse sentido, interessa dizer que:

Os direitos do homem, por mais fundamentais que sejam, são direitos históricos, ou seja, nascidos em certas circunstâncias, caracterizados por lutas em defesa de novas liberdades contra velhos poderes, e nascidos de modo gradual, não todos de uma vez e nem de uma vez por todas (BOBBIO, 1992, p.5).

\footnotetext{
9 Pessoas físicas ou jurídicas, nacionais ou estrangeiras, públicas ou privadas, ou mesmo entes despersonalizados (massa falida, espólio etc.), estrangeiros residentes ou de passagem pelo território nacional. Hodiernamente, fala-se, inclusive, em animais como sujeitos de direitos (vide a teoria abolicionista animal).
} 
Apesar de os direitos humanos ${ }^{10}$ existirem faz muito tempo, frutos da própria qualidade intrínseca à humanidade, que é anterior e superior a todo ordenamento jurídico positivado, só passaram a ser formalmente reconhecidos a partir das declarações solenes (CUNHA JÚNIOR, 2008), frutos dos movimentos constitucionais, ganhando dimensão jurídica e natureza de direito fundamental. $\mathrm{O}$ reconhecimento desses direitos começou no século XIII, mais especificamente, em 1215, quando a Magna Charta Libertatum, pacto firmado entre o Rei João Sem Terra e os Bispos e Barões ingleses, garantiu alguns direitos fundamentais como o devido processo legal, a liberdade de locomoção e a propriedade, apesar de ter garantido privilégios feudais somente aos nobres ingleses (CUNHA JÚNIOR, 2008). Posteriormente, no século XVII, destacaram-se as declarações inglesas entre as quais a Petition of Rights, de 1628, elaborada pelo Parlamento Inglês, por meio do qual se pleiteou o efetivo cumprimento pelo Rei dos direitos previstos na Magna Carta; o Habeas Corpus Act, de 1679, que reforçou as reivindicações de liberdade e, finalmente, a mais importante de todas as Declarações inglesas, o Bill of Rights, de 1689, que significou a passagem do regime monárquico absoluto para a monarquia constitucional (CUNHA JÚNIOR, 2008), rompendo com as bases políticas da época.

Segundo Comparato (2003, p. 93),

[...] o essencial do documento consistiu na instituição da separação de poderes, com a declaração de que o Parlamento é um órgão precipuamente encarregado de defender os súditos perante o Rei, e cujo funcionamento não pode, pois, ficar sujeito ao arbítrio deste. Ademais, o Bill of Rights veio fortalecer a instituição do júri e reafirmar alguns direitos fundamentais dos cidadãos, os quais são expressos até hoje, nos mesmos termos, pelas Constituições modernas, como o direito de petição e a proibição de penas inusitadas ou cruéis.

No entanto, as declarações inglesas, apesar do seu relevante valor histórico, não podem ser consideradas como a "certidão de nascimento" dos direitos fundamentais, pois só se destinavam a parcela de seu povo. Foi no século XVIII, com revolução liberal na França e a independência das colônias inglesas na América do Norte, que ocorreu a transição dos direitos de liberdade do povo inglês para os direitos fundamentais constitucionais. A Declaração do Bom Povo da Virgínia de 1776, baseada nos direitos

\footnotetext{
${ }^{10}$ Cabe salientar aqui que, a despeito da existência de diferenciação terminológica entre direitos do homem, direitos humanos e direitos fundamentais, nesta pesquisa utilizar-se-ão os termos indiscriminadamente, desprezando-se o caráter conceitual e prezando o significado, na prática.
} 
naturais e imprescritíveis do homem, preocupou-se, com a fundação de um governo democrático e a limitação de poderes. Em seguida, a Declaração Francesa dos Direitos do Homem e do Cidadão de 1789, "proclamava os princípios da liberdade, da igualdade, da propriedade e da legalidade e as garantias individuais liberais" (SILVA, 2008, p. 158). Por último, a Declaração Universal dos Direitos do Homem, adotada pela Assembleia Geral das Nações Unidas, em 1948, constituiu "um conjunto indissociável e interdependente de direitos individuais e coletivos, civis e políticos, econômicos, sociais e culturais" (CUNHA JÚNIOR, 2008, p. 555).

Assim são afirmados historicamente os direitos fundamentais, que são aqueles utilizados pela doutrina para identificar os direitos inerentes à pessoa humana quando positivados por um ordenamento jurídico específico. Nesse sentido, aponta Silva Neto (2007, p. 461), para o qual "a designação de "fundamentais" é dedicada àquele conjunto de direitos assim considerados por específico sistema normativo-constitucional”.

$\mathrm{Na}$ atual Constituição Brasileira de 1988, esses direitos estão elencados em seu art. $5^{\circ}$ com nada menos que setenta e oito incisos, protegidos pela cláusula de irredutibilidade prevista no art. 60, $\S 4^{\circ}$, IV (CUNHA JÚNIOR, 2008) ${ }^{11}$.

O tema que ganha relevância no campo dos direitos fundamentais para a presente pesquisa encontra-se no debate paradoxal entre o direito à saúde (art. 196 da Constituição Federal de 1988) e ao meio ambiente sustentável (art. 225 da Constituição Federal de 1988) ${ }^{12}$ versus o direito da população indígena aos costumes de seu povo (art. 231 da Constituição Federal de 1988) ${ }^{13}$. Ambos possuem o mesmo peso e

\footnotetext{
${ }^{11}$ A Constituição ainda prevê outros direitos considerados fundamentais, dispostos da seguinte forma: "Dos Direitos Sociais" (arts. 6a 11); "Da Nacionalidade" (arts. 12 e 13); "Dos Direitos Políticos (arts. 14 a 16); e "Dos Partidos Políticos" (art. 17), sem falar nos direitos sociais e transindividuais espalhados por todo o texto constitucional, a exemplo da Segurança Pública (art. 144), da Seguridade Social - saúde, previdência e assistência social. (arts. 194 a 202), da Assistência Social (arts. 203 e 204), da Educação (arts. 205 a 214), da Cultura (arts. 215 e 216), do Desporto (art. 217), da Ciência e Tecnologia (arts. 218 a 219), da Comunicação Social (arts. 220 a 224), do Meio Ambiente (arts. 225), da Família, da Criança, do Adolescente, do Jovem e do Idoso (arts. 226 a 230) e dos Índios (arts. 231 e 232).

${ }^{12}$ A respeito do meio ambiente, da mesma forma, existe um sem-número de documentos nacionais e internacionais que focam a necessidade de sustentabilidade, educação ambiental. Para o presente estudo, a nova Lei 12.305/2010, institui a Política Nacional de Resíduos Sólidos é uma das normativas relevantes.

${ }^{13}$ Além das normas constitucionais, existem inúmeras normas que protegem os direitos e interesses dos índios, a exemplo do Decreto Trabalho - OIT sobre Povos Indígenas e Tribais e a Declaração das Nações Unidas sobre os Direitos dos Povos, garantem a supremacia dos direitos humanos frente a qualquer crença. Posto isto, de acordo com o artigo $8^{\circ}$ da Convenção $n^{\circ} 169$ da Organização Internacional do Trabalho - OIT, promulgada pelo Decreto $\mathrm{n}^{\circ} 5.051$ de 2004, "Esses povos deverão ter o direito de conservar seus costumes e instituições próprias, desde que eles não sejam incompatíveis com os direitos fundamentais definidos pelo sistema jurídico nacional nem com os direitos humanos internacionalmente
} 


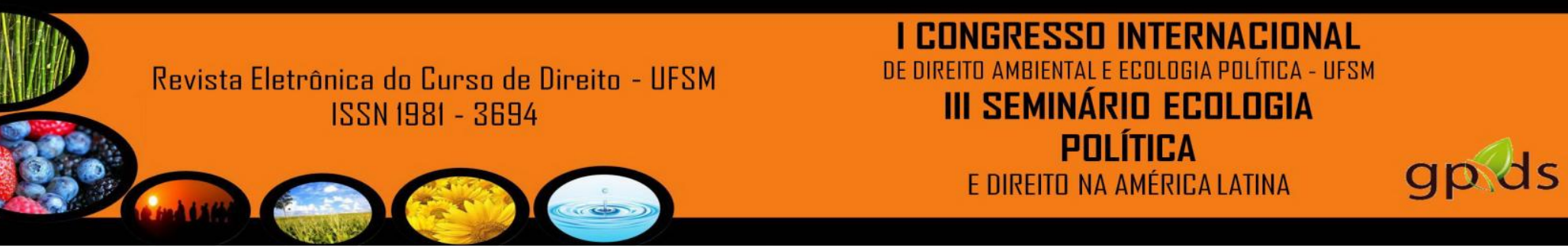

importância e são fundamentados no princípio-vetor da dignidade da pessoa humana, que, no entendimento de Sarlet, significa,

[...] a qualidade intrínseca e distintiva reconhecida em cada ser humano que o faz merecedor do mesmo respeito e consideração por parte do Estado e da comunidade, implicando, neste sentido, um complexo de direitos e deveres fundamentais que assegurem a pessoa tanto contra todo e qualquer ato de cunho degradante e desumano, como venham a lhe garantir as condições existenciais mínimas para uma vida saudável, além de propiciar e promover sua participação ativa e co-responsável nos destinos da própria existência e da vida em comunhão com os demais seres humanos, mediante o devido respeito aos demais seres que integram a rede da vida (SARLET, 2009, p. 67).

Assim, os direitos fundamentais, encontram seus limites nos próprios direitos consagrados pela Constituição gerando um paradoxo (colisão de direitos fundamentais). Quando a preservação de um direito fundamental agride a integridade de outro direito de mesma natureza, impõe-se proceder à compatibilização entre os mesmos, através dos princípios de interpretação constitucional com destaque o princípio da concordância prática/harmonização/pondereção e para a proporcionalidade, tendo como parâmetro a dignidade da pessoa humana, posto que, como assevera Piovesan (2004, p. 319), “o valor da dignidade humana impõe-se como núcleo básico e informador do ordenamento jurídico brasileiro, como critério e parâmetro de valoração a orientar a interpretação e compreensão do sistema constitucional instaurado em 1988".

No presente caso, a hipótese inicial para compatibilização dos direitos fundamentais em choque e que representa menor dano à dignidade da pessoa humana situa-se na concretização da educação ambiental ${ }^{14} \mathrm{e}$ políticas públicas, especialmente para as tribos indígenas nas cidades.

Nesse sentido, Capra (2000) ressalta a necessidade da alfabetização ecológica da humanidade. É exatamente nesse ponto que ingressa a transdisciplinaridade como uma forma de educação pioneira de um novo saber humano, que possua de forma a

reconhecidos". Da mesma forma, estabelece o artigo 34 da Declaração das Nações Unidas sobre os Direitos dos Povos Indígenas que: "Os povos indígenas têm o direito de promover, desenvolver e manter suas estruturas institucionais e seus próprios costumes, espiritualidade, tradições, procedimentos, práticas e, quando existam, costumes ou sistema jurídicos, em conformidade com as normas internacionais de direitos humanos".

${ }^{14}$ Interessante citar que Morin ensina que há que se fazer uma total reorganizaçao da educação, impondose o uso da interdisciplinariedade no ensino. O pensador aduz que os sete saberes necessários para o ensino do futuro são: I. reconhecer as cegueiras do conhecimento, seus erros e ilusoes; II. assumir os princípios de um conhecimento pertinente; III. condiçao humana; IV. identidade planetária; V. enfrentar as incertezas; VI. compreender e VII. a ética do gênero humano. Referência feita em: MORIN, Edgar. Introdução ao pensamento complexo. Traduzido por Dulce Matos. 4. ed. Lisboa: Piaget, 2003. 
Percebe-se, através da fala acima, que, além do claro interesse na preservação do meio ambiente, os kaingang usam a terra em que vivem para o sustento e educação. Quanto à saúde, na entrevista, ele ressalta que os habitantes do acampamento pouco adoecem, e que quando isso acontece, eles são bem atendidos no "postão" (sic) e ganham medicações (ENTREVISTA COM O REPRESENTANTE DO ACAMPAMENTO KAINGANG DA RODOVIÁRIA DE SANTA MARIA, 2012). Ou seja, paradoxalmente à omissão do Estado em atender às demais demandas (tanto que foi necessária uma audiência pública no município), os índios entendem que o direito á saúde está efetivado.

Ainda, relacionando a pesquisa ao mínimo possível, vertente da dignidade humana que reflete o atendimento às necessidades básicas pelo Estado, o entrevistado afirma que

[...] Sanitários sempre abrimos buracos e tapamos logo. A água a CORSAN improvisou e colocamos uma manga para vir a água até aqui no acampamento. Falta luz...usamos lamparinas e o fogo onde fizemos a comida, mesmo sendo perigoso....cuidamos muito. (sic) (ENTREVISTA COM O REPRESENTANTE DO ACAMPAMENTO KAINGANG DA RODOVIÁRIA DE SANTA MARIA, 2012)

Nota-se que, em relação ao direito sanitário, talvez o próprio costume do povo indígena reflita a falta de exigências maiores deles para com o Estado. Entretanto, com humildade, o próprio representante da comunidade kaingang aduz que eles estão aguardando que as autoridades municipais dêem a eles uma infra-estrutura melhor: "[...] Se um dia isso acontecer, vamos ser muito felizes. Cuidaremos de tudo e assim poderemos dizer que estamos cuidando do que é nosso." (ENTREVISTA COM O REPRESENTANTE DO ACAMPAMENTO KAINGANG DA RODOVIÁRIA DE SANTA MARIA, 2012).

Ressalta-se, nesse sentido, a notória vulnerabilidade dos pesquisados, não só pela determinação do Conselho Nacional de Saúde, mas, especialmente, por habitarem a América Latina, que tem um povo vulnerável pela própria heterogeneidade. Assim,

A fragilidade e a vulnerabilidade em que se encontram algumas das populações de países considerados pobres e em desenvolvimento pode permitir que estudos considerados inaceitáveis em países desenvolvidos sejam realizados em locais menos favorecidos. (WOLTMANN, 2006, p. 77) 


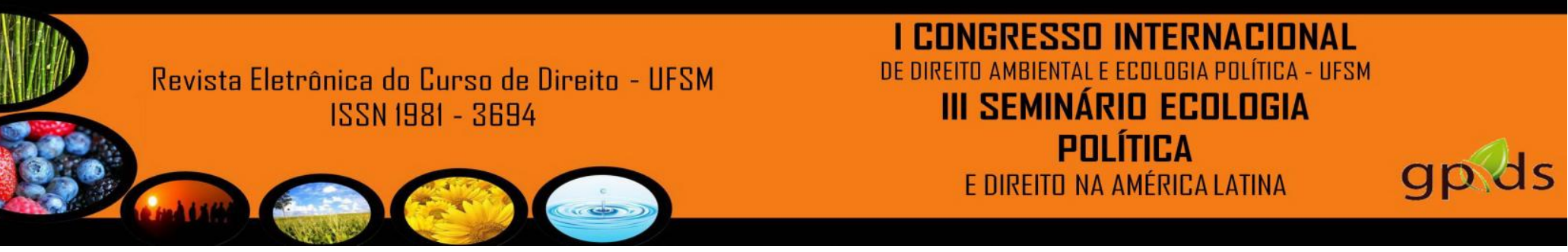

REFERENCIAS

$1^{\circ}$ ASSEMBLÉIA POPULAR INDÍGENA DA CIDADE DE SANTA MARIA/RS: A PRESENÇA INDÍGENA NO MUNICÍPIO DE SANTA MARIA/RS. Políticas Públicas e Responsabilidades. Disponível em: <xa.yimg.com/kq/groups/8553128/1503815342/name/RELEASE.doc> Acesso em: 27 mai. 2011.

BOBBIO, Norberto. A Era dos Direitos. Tradução de Carlos Nelson Coutinho. Rio de Janeiro: Campus, 1992.

BRASIL. Constituição da República Federativa do Brasil. Disponível em: <http://www.planalto.gov.br/ccivil_03/constituicao/constitui\%C3\%A7ao.htm > Acesso em: 27 mai. 2011.

CAMARA MUNICIPAL DE VEREADORES DE SANTA MARIA. Demandas de povos indígenas discutidas em reunião pública. Disponível em: $\langle$ http://www.camarasm.rs.gov.br/2010/?conteudo=noticia\&id=439> Acesso em: 27 mai. 2011.

1 CARVALHO, Priscila D, de. Povos reivindicam políticas; Estado esboça respostas. In: Carta Maior. Disponível em: <http://www.cartamaior.com.br/templates/materiaMostrar.cfm?materia_id=13969> Acesso em: 26 mai.2011

COMPARATO. Fábio Konder. A Afirmação Histórica dos Direitos Humanos. 3. ed. São Paulo: Saraiva, 2003.

CUNHA JÚNIOR, Dirley da. Curso de Direito Constitucional. 2. ed. Salvador: Jus Podium, 2008.

DINIZ, Débora; GUILHEM, Dirce; SCHÜKLENK, Udo. Ética em Pesquisa: Experiência de treinamentos em países sul-africanos. Traduzido por Ana Terra Mejia, Déboa Diniz e Lara de Paula. Brasília: LetrasLivres: UnB, 2005.

ESTADO DO RIO GRANDE DO SUL. Histórico da Imigração no RS. Disponível em:

〈http://www.turismo.rs.gov.br/uploads/1239121722Historico_da_Imigracao_RS.pdf>

Acesso em: 27 mai. 2011.

ENTREVISTA COM O REPRESENTANTE DO ACAMPAMENTO KAINGANG DA RODOVIÁRIA DE SANTA MARIA. Comunidade indígena kaingang na cidade de Santa Maria/RS: é possível fiscalizar e proteger o meio ambiente sem prejudicar a cultura indígena? [15 abril 2012]. Entrevistadoras: Dorilda Fantinel Woltmann e Michele Soares Quadros. Entrevista concedida para pesquisa PIBIc/UNICRUZ e pesquisa de Pós-Graduação do Centro Universitário Barão de Mauá. 


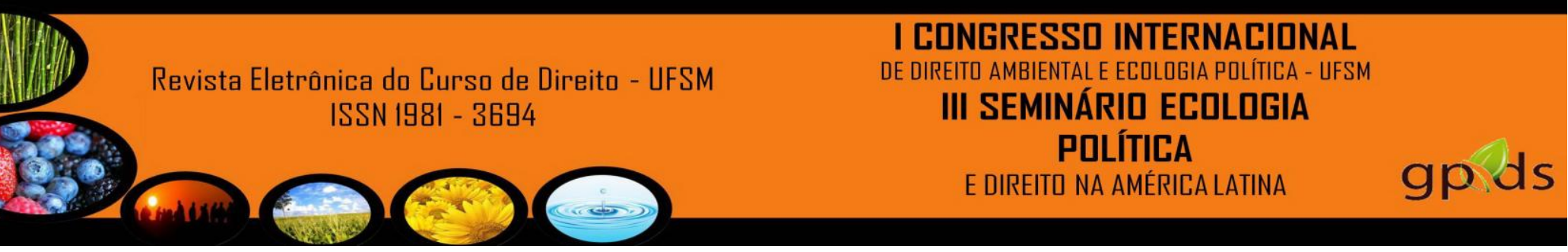

FLORES, Moacyr. Memorial do Rio Grande do Sul. In: Caderno de História, no 38. Rio Grande do Sul: Secretaria da Cultura, 2010. Disponível em: http://www.memorial.rs.gov.br/cadernos/guerraseconflitos.pdf

FUNAI. Legislação Indigenista Brasileira e Normas Correlatas. 2005. Disponível em: $\quad\langle$ http://www.funai.gov.br/projetos/Plano_editorial/Pdf/Legisl/capitulo-01.pdf >. Acesso em: 27 mai. 2011.

INSTITUTO SÓCIO AMBIENTAL. Povos Indígenas no Brasil. Disponível em: http://pib.socioambiental.org/pt/povo/kaingang/287

MARTINS, José de Souza. Os camponeses e a política no Brasil. Petrópolis: Vozes, 1983.

MINAYO, M. C. S. O Desafio do Conhecimento: Pesquisa Qualitativa em Saúde. São Paulo: Hucitec; Rio de Janeiro: Abrasco, 1994.

MELLO, Reynaldo França Lins de. Em busca da sustentabilidade da organização antropossocial através da reciclagem e do conceito de auto-eco-organização. (Dissertação). Curitiba: UFPR, 1999.

MORIN, Edgar. Introdução ao pensamento complexo. Traduzido por Dulce Matos. 4. ed. Lisboa: Piaget, 2003.

PIOVESAN, Flávia. Direitos Humanos e o Direito Constitucional Internacional. São Paulo: Max Limonad, 2004.

SARLET, Ingo Wolfgang. Dignidade da pessoa human e direitos fundamentais na Constituição Federal de 1988. 7. ed. Porto Alegre: Livraria do Advogado Ed., 2009.

VEIGA, Juracilda; D'ANGELIS, Wilmar da Rocha. Portal Kaingang. Disponível em: http://www.portalkaingang.org/index_aldeia_principal_1.htm

WOLTMANN, Angelita. Comitês de Ética em Pesquisa no âmbito latino-americano (Brasil Argentina): transdisciplinariedade em prol da dignidade humana. (Dissertação). Santa Maria: UFSM, 2006.

ZARTH, Paulo Afonso. História agrária do Planalto Gaúcho 1850 - 1920. Ijuí: Editora da UNIJUI, 1997. 